Usage, Usability, and Utility of 3D City Models, 02009 (2012)

DOI: $10.1051 / 3 \mathrm{u} 3 \mathrm{~d} / 201202009$

(C) Owned by the authors, published by EDP Sciences, 2012

\title{
A generalized approach for historical mock-up acquisition and data modelling: Towards historically enriched 3D city models
}

\author{
B. Hervy ${ }^{1,2}$, R. Billen ${ }^{3}$, F. Laroche ${ }^{2}$, C. Carré ${ }^{3}$, M. Servières ${ }^{4}$, \\ M. Van Ruymbeke ${ }^{5}$, V. Tourre ${ }^{4}$, V. Delfosse ${ }^{3}$ and J.-L. Kerouanton ${ }^{6}$ \\ ${ }^{1}$ Musée d'histoire de Nantes - Château des ducs de Bretagne, Nantes, France \\ ${ }^{2}$ LUNAM Université, École Centrale Nantes, IRCCYN UMR CNRS 6597, Nantes, France \\ ${ }^{3}$ Geomatics Unit, Department of Geography, University of Liège, Belgium \\ ${ }^{4}$ LUNAM Université, École Centrale Nantes, CERMA UMR CNRS 1563, Nantes, France \\ ${ }^{5}$ CARE Réseau des bibliothèques, University of Liège, Belgium \\ ${ }^{6}$ LUNAM Université, Centre François Viète, Université de Nantes, France
}

\begin{abstract}
Museums are filled with hidden secrets. One of those secrets lies behind historical mock-ups whose signification goes far behind a simple representation of a city. We face the challenge of designing, storing and showing knowledge related to these mock-ups in order to explain their historical value. Over the last few years, several mock-up digitalisation projects have been realised. Two of them, Nantes 1900 and Virtual Leodium, propose innovative approaches that present a lot of similarities. This paper presents a framework to go one step further by analysing their data modelling processes and extracting what could be a generalized approach to build a numerical mock-up and the knowledge database associated. Geometry modelling and knowledge modelling influence each other and are conducted in a parallel process. Our generalized approach describes a global overview of what can be a data modelling process. Our next goal is obviously to apply this global approach on other historical mock-up, but we also think about applying it to other 3D objects that need to embed semantic data, and approaching historically enriched 3D city models.
\end{abstract}

\section{INTRODUCTION}

Historical mock-ups are very useful for historians as they show us the shape of a city few decades or centuries ago. They give us information about the mock-up construction techniques. Besides the fact that these mock-ups are interesting for scientists, they can be used to attract people to historical topics, as they are very expressive by themselves.

Everybody can easily look at a mock-up of a city or a building, but few people can really understand what lies behind these objects. The historical questions raised by these objects are not obvious, and if you don't have a guide or a full book explaining all the extracted knowledge, you will only remains at watching a nice object. So the problem is to use this singular object to attract people and to give them an easy access to its hidden knowledge. To solve this issue, we propose to use digital technologies to valorise these mock-ups. This digital processing of cultural heritage objects implies geometry scanning and knowledge modelling problems.

Several research works have been driven from this approach, but most of the time focusing on specific objects and without a holistic approach. Then, our goal is to build a generalized approach for processing the data. We show that we can unify two existing processes devoted to data acquisition and

This is an Open Access article distributed under the terms of the Creative Commons Attribution License 2.0, which permits unrestricted use, distribution, and reproduction in any medium, provided the original work is properly cited. 
modelling of historical mock-ups. This generalized approach will be illustrated on mock-ups of Nantes and Liege in projects called Nantes 1900 and Virtual Leodium.

The paper is structured as follow. The section 2 presents a summary of previous works in the field of mock-up digitalisation. In section 3, we analyse the approaches of the Nantes 1900 and Virtual Leodium projects. Then we propose a generalised approach in section 4. In section 5, we discuss the proposed approach and the related developments focussing on three aspects: usability, usage and utility. Finally, we conclude in section 6 .

\section{PREVIOUS WORKS}

Mock-ups digitalisations are done in various projects to obtain a 3D model. But, most of the time, theses 3D models are not embedded in a larger process, including knowledge modelling and data enrichment.

Few projects propose to digitize a large heritage object and to create a virtual model with many levels of details that are chosen by the users [1-5]. Data can be acquired by photographic systems [1] or $3 \mathrm{D}$ model can be extracted from pictures [2]. Historical documents are also used to complete the knowledge on the mock-ups [3-5].

Nantes museum is one of the most famous museums in France containing many interactive applications dedicated to visitors. For example, one of them helps to discover the city of Nantes in 1757. The open source software proposes to navigate into a virtual world thanks to Ogre 3D. However, those kinds of projects are not similar to Nantes1900 project as they propose a virtual model reconstructed thanks to historical maps or writings and not directly from a 3D physical mock-up; moreover there is no interaction between the "virtual world" and the "real life".

The main idea developed in this communication is the use of virtual technologies for cultural heritage enhancement (data acquisition and modelling). Indeed, objects studied by our research teams belong to scientific and/or technical domains. Contrary to examples presented in this very short state of the art, the specificity of all those projects is that the work is done manually; nothing is automatic. Few algorithms are presented but they only state the followed process [6].

Every kind of digitization raised numerous problems. One of the most important here is that it is impossible to visualize the enormous quantity of points acquired. There is no software that can manipulate easily 200 millions of points. Concerning Nantes1900 and Liège projects, it would be impossible to do it manually due to the amount of data in the $3 \mathrm{D}$ cloud of points or in the historical data.

\section{ANALYSIS OF EXISTING APPROACHES}

We will describe each of the two processes, in Nantes and Liège with the same terms and explain the respective advantages and drawbacks of each method, in order to merge the knowledge of the preceding processes to extract a global model.

In the Liège process, the geometric data extraction is done from data sources and then this geometric data helps the knowledge modelling. In the Nantes process, it is done in a completely opposite manner, the knowledge modelling is done directly from the data sources and then it helps the geometric modelling. The last step of data fusion between geometric model and knowledge model is common in the two processes.

\subsection{Virtual Leodium}

The Virtual Leodium system can be decomposed into four components (Figure 1): an information model and database creation module, two information acquisition and integration modules and finally a virtual information system. The central component is a knowledge database, which is built using a specific historical model linking historical sources with urban objects. This model, which is detailed below in 


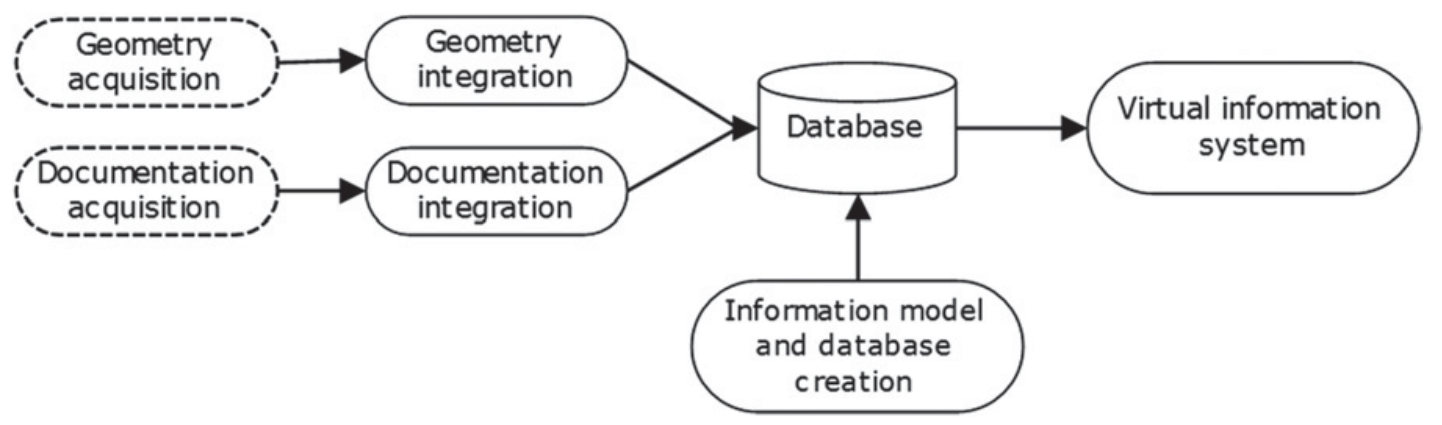

Figure 1. General Virtual Leodium workflow.

the paper, is first written using UML and then converted into a relational model to match with the ArcGIS database format.

The created database is then populated with two types of information: historical documentation and 3D objects. The historical documentation is composed mainly of texts and images describing the mockup construction but also other information about the historical context of the represented part of the city. The 3D objects are derived from the original mock-up. It has been scanned using an optical inspection technique (projected-fringes) allowing recording and processing the information that defines the precise 3D shape and chromatic characteristics of an object [7]. The result is more than 650 individual scan which then need to be cleaned and merged before obtaining a final digital surface model. Individual object reconstruction is done with the $3 \mathrm{D}$ computer graphics software Maya using the digital surface model and photos of the mock-up. Every building face has been photographed; resulting images are rectified and used as a draping texture.

The virtual information system is itself composed in two modules: one is the 3D viewer; the other is the source browser. 3D objects and sources are linked together; selecting a 3D object or a source allows retrieving and displaying the corresponding sources or objects.

The whole application is developed in Java. It relies on ArcGIS 10 for storing geometries and the semantic data. It also takes benefits from the ArcScene API available in Java for displaying and navigating in the 3D scene. For the semantic data viewer, a homemade abstraction layer has been developed: it automatically generates the GUI based on a high level description of what has to be displayed. That way, the application can quickly be adapted to modifications in the data model.

Beside acquisition techniques and system prototype technical developments, the data model development should not be neglected. It is indeed the foundation of the system; its relevance impacts on the usability and consequently the utility of the system.

In this paper, we present a simplified conceptual model without attributes (Figure 3). It is composed of several objects. In practical terms, the departure point of any historical modelling is always the information given by one or more sources. "Source" object stores all historical documentations. Documentations might have multiple and sometime contradictory interpretations. Each interpretation, made by a "Person" generates a "Version". This object is central in our approach. An interpretation can generate a "Geometry", e.g. complete geometric representation of a specific building or building element, or an historical "Fact".

The object "City Object" is taken from CityGML. In the implemented model, CityGML objects are used (Building, Building element, Vegetation, Terrain, etc.). They are specializations of "City Object". In a higher-level approach, a more general object called "Information container" can be considered, but in this Virtual Leodium application, the use of "City Object" is appropriate as only urban objects are manipulated. The use of CityGML was also motivated for interoperability purposes. "City Object" has geometrical representations only through its association with a "Geometry" (and 


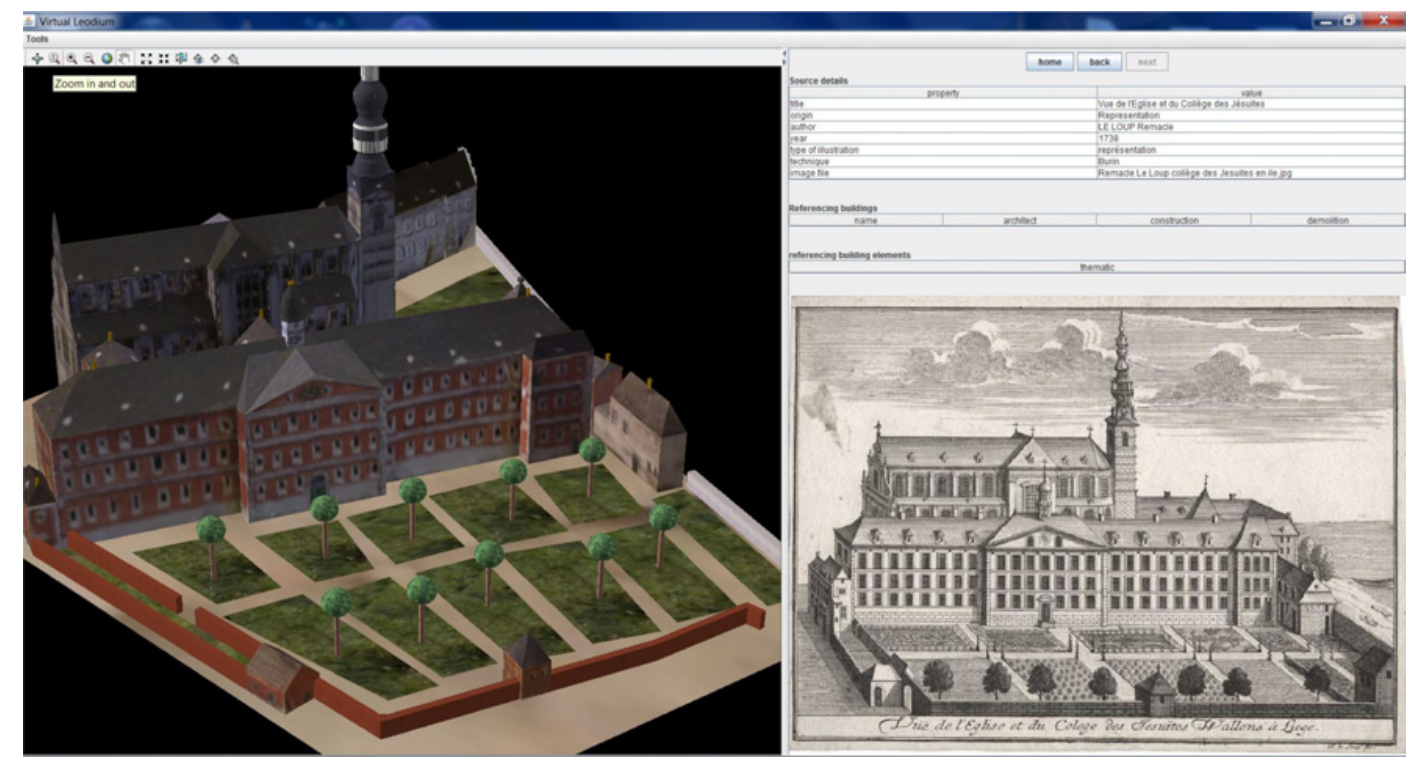

Figure 2. A snap shot of the current version of the Virtual Leodium prototype.

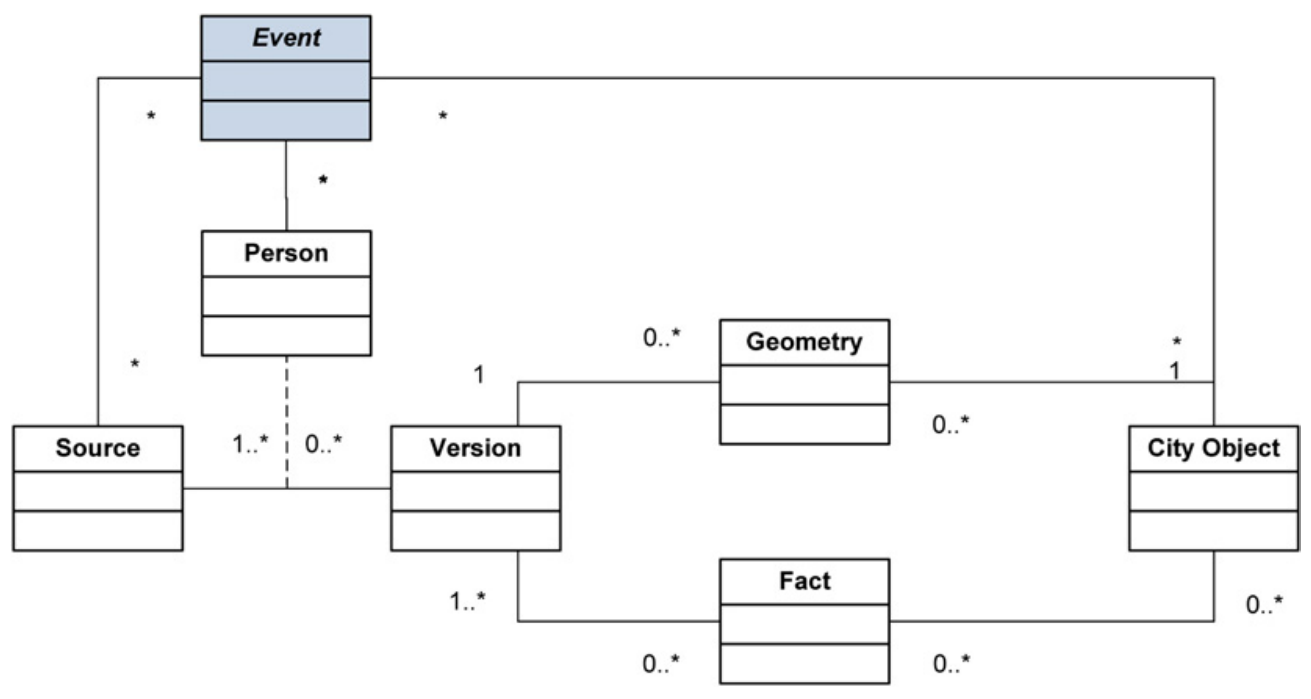

Figure 3. Virtual Leodium data model.

therefore with a version). "Facts" can be associated to "City Object". "Person" stores people that can act as author (the architect of a building), as subject (person represented on a painting) or simply associated with another object. Finally "Event" deals with time and interaction between "Person", "Source" and "City Object".

The model currently implemented in the prototype is very similar to the one presented in figure 3. The "Event" object has not been implemented (in grey in the figure); this important modification was necessary to respect the short time development of the software. Consequently, "Person" is directly linked to "Sources" and "City Object". It is worth to mention that in its current stage, the "version" 


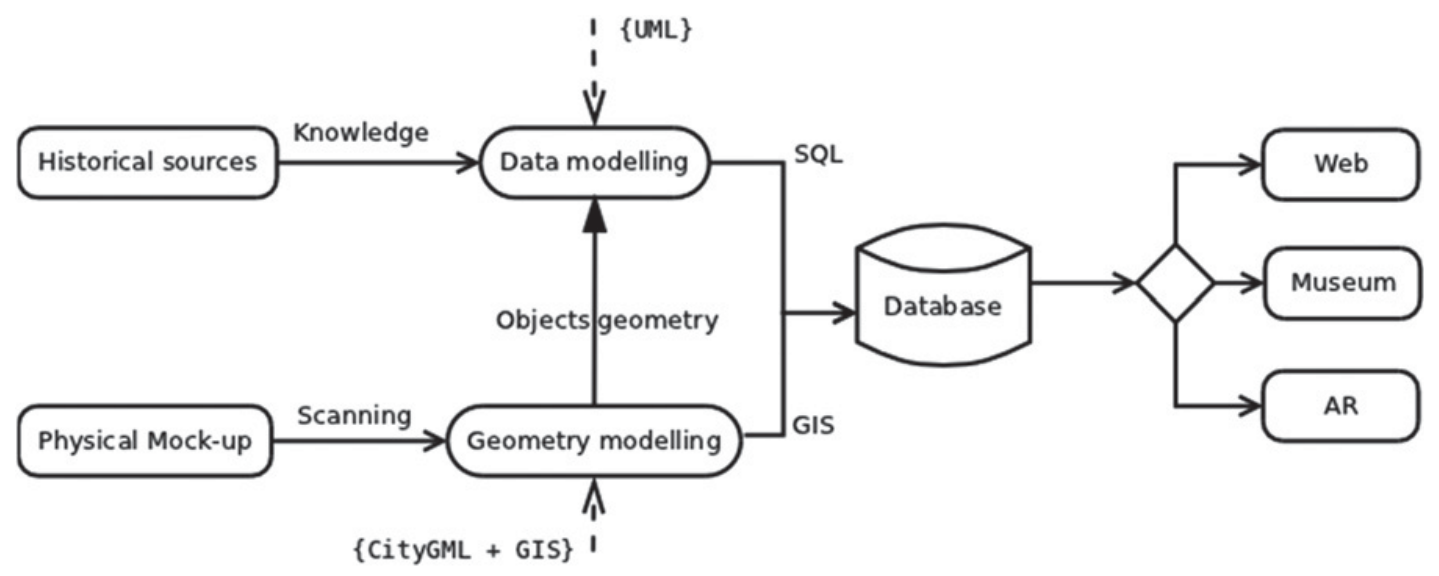

Figure 4. Techno-archaeological global process of Nantes1900 project.

object is underused. Indeed, the data model has not been developed having in mind only the Rhul's mock-up; it aims at being a basic model for historical information system in general. Therefore, when applied to Virtual Leodium project, the source of information being exclusively the original mock-up (and its associated documentation), almost all of the 3D objects are associated to a geometry coming from the same version (the Rhul's one). In summary, the production of information has been mainly driven by the creation of $3 \mathrm{D}$ virtual objects that then are contextualised with other historical information. In the future, the objective is to consider other sources of information that can then slightly change the information production process.

\subsection{Nantes 1900}

Nantes1900 data processing is based on knowledge from historical sources. An UML model is first designed to fit with historical knowledge needs. But the model is also expected to store the geometry related to physical studied objects. These geometrical characteristics derived from mock-up scanning and 3D mock-up treatment. Nantes 1900 mock-up was digitized using a scanner that acquired a 3D cloud of points.

A database has been designed for interconnecting the different data manipulated in Nantes 1900 project. Historians use primary and secondary sources for understanding the past. Thanks to those historical information related to the city, they produced contextual knowledge. Next they have formalized this knowledge into a database.

Technologies used are PostgreSQL with a PostGIS add-on for geometrical data support. Both are licensed under copy left licenses (respectively BSD and GNU GPL). PostgreSQL allows us to deal with a relational and object-oriented model.

In order to reach the main objective that is to create an evolutive and collaborative knowledge database, the UML model is designed as a meta-model on purpose.

Therefore, there are only four main entities:

- "Object" entity which stores both real objects' knowledge and abstract concepts (like an ontology) related to city objects. Real objects have geometrical and temporal attributes (when known) whereas abstract concepts don't.

- "Temporal geometry" entity stores geometrical data related to object entities. Several geometries with temporal index can be linked to object entity so that we can manage the whole evolution of an object in history. 


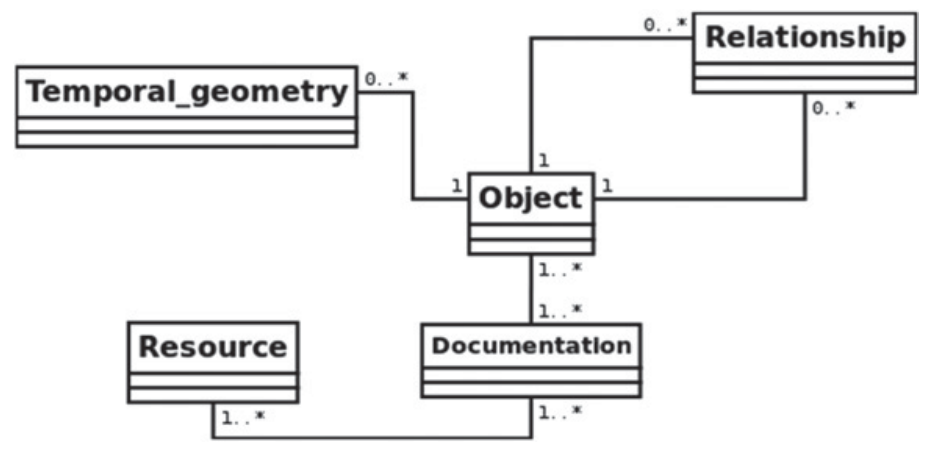

Figure 5. Nantes 1900 data model.

- "Resource" entity allows to store historical sources (e.g. from archives). Two main types of resources have been identified: "Text-based" and "Graphical". Object-oriented model allows dealing with inheritance for resources management. As far as historical resources are concerned, the goal is not to create a full ontology but to redirect towards resources primary sources.

- "Relationship" entity is the implementation of a generic "relationship". Indeed, several relationships are possible due to the generic storage of objects. Currently, there is two generic kinds of relationship:

1. Direct: between 2 real objects.

2. Indirect: between a real object and an abstract concept.

Specific web application has also been designed to access this database on the web. It allows users to add, alter and obviously consult data. Others applications based on this knowledge database are currently in their design phase, such as a multi-touch museographic project.

Figure 6 illustrates how historical data is connected through the data model. Data sample is related to a specific quarter of Nantes harbour called "Saint-Similien" which allows us to try our hypothesis on a limited area. Graph nodes represent "object" entities (real objects and abstract concepts) and edges represent "relationship" entities.

"Saint-Similien" sample starts with a base of 28 "object" entities, on which historical research have been done, resulting in historical sheets for each one of them. Each "object" has several keywords that historians have identified as related abstract concepts and related physical objects. These keywords automatically generate new "object" entities in our database and the links are stored as "relationship" entities, so there are finally 171 "object" entities (nodes) and 246 relationships (edges) created. As far as Nantes 1900 global project is concerned, we generate about 1500 "object" entities and more than 3000 relationships for a starting base of about 300 historical sheets.

\section{GENERALISED APPROACH PROPOSITION}

This global model proposition is done thanks to the analysis of the two preceding data modelling processes, where we show a clear difference into the extraction of the geometric data and the knowledge data. A more comprehensive analysis can be found here [8]. Nevertheless, we pay attention to use into this analysis the same terms in order to identify the steps that have identical goals, sometimes with different inputs and outputs. Now, by merging the two processes, we show that all the constraints can be integrated into one global process, and that the two preceding process, virtual Leodium and Nantes 1900, can be easily retrieved by following a different path into this global process. 


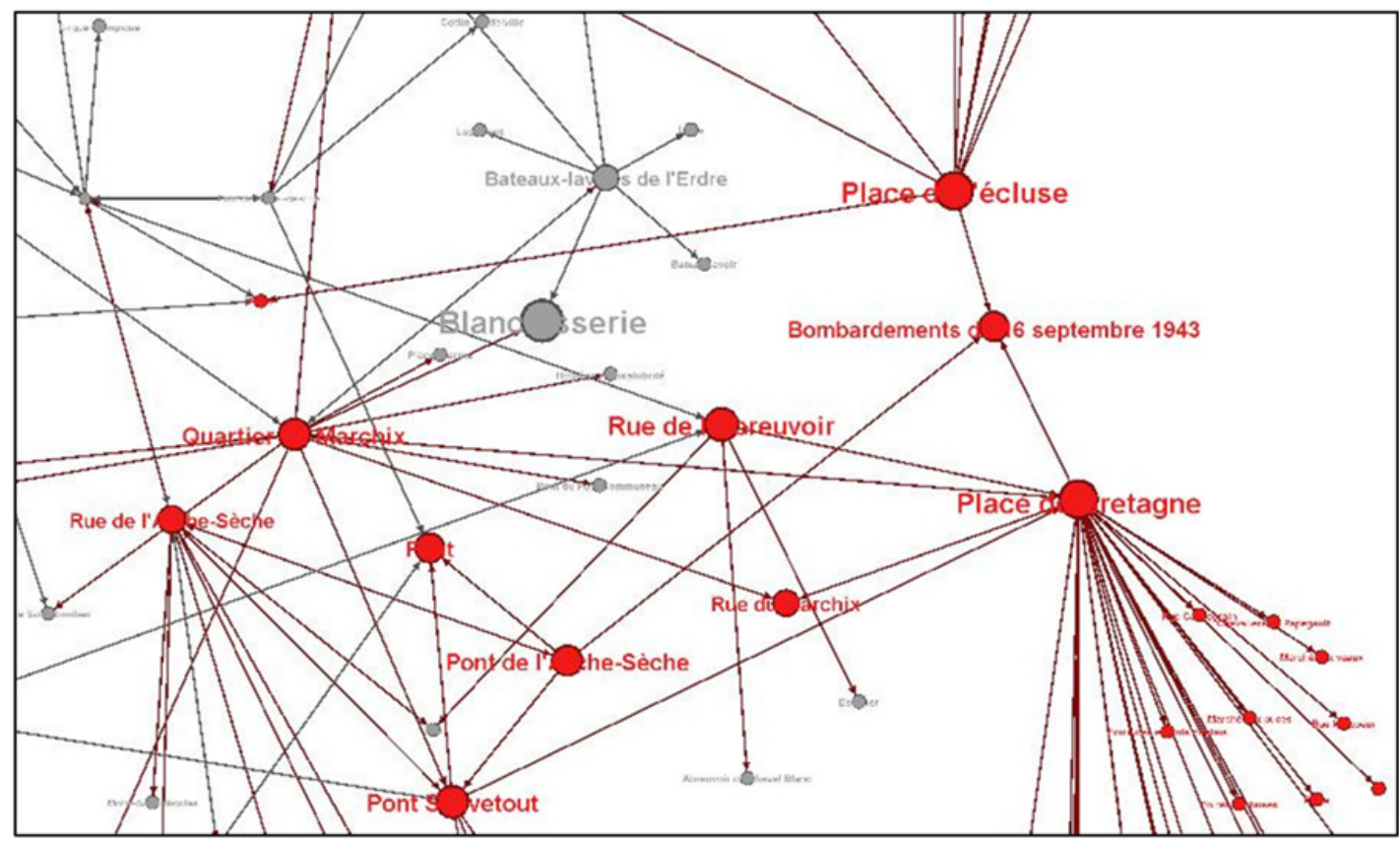

Figure 6. Historical data structure example.

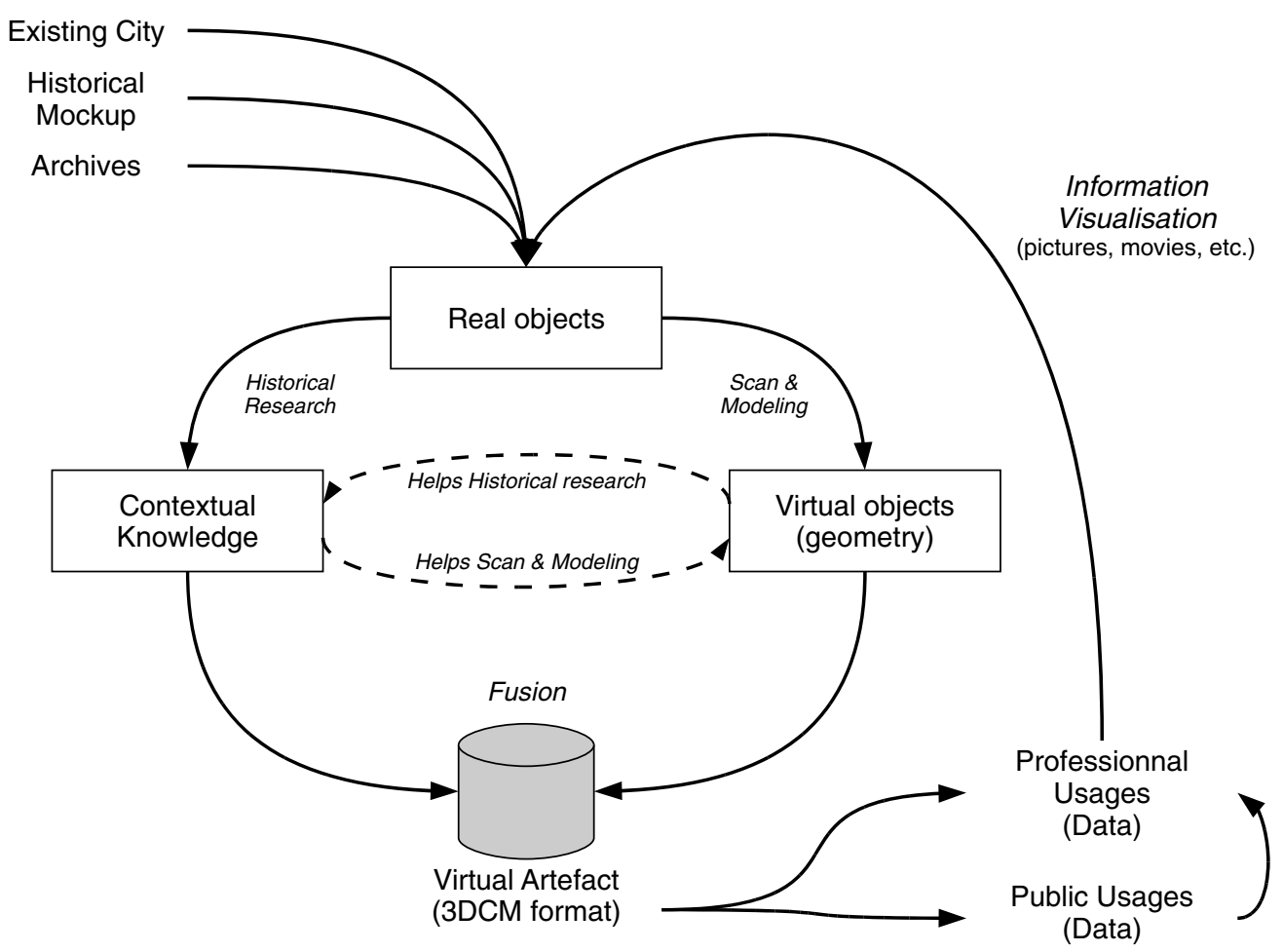

Figure 7. Global historical mock-up data process. 
Usage, Usability, and Utility of 3D City Models

\section{- Primary data}

The primary data is the historical object, or raw material, without any interpretation. This primary data obviously contains the historical mock-up, but it can be enriched with historical elements from the actual city (facades, statues, details, etc.) and with archives (maps, cadastre, letters, postcards, etc.). All this material, as testimony from the past, is the basis of all the modelling steps. This primary data is found into the two existing mock-up modelling processes, and globally speaking into all modelling processes.

- Secondary data

The secondary data is the data generated by the analysis of the primary data. Most of the time, this is an interpretation of the raw material, or elements produced at the end of the process. This interpretation is done by professionals based on scientific or information visualisation, and can be also based on public usage. It can be seen as a feedback into the process, as these secondary data produce contextual knowledge that is directly integrated into the process.

\section{- Virtual 3D Object}

From the primary data containing 3D information (mock-up and existing city), there is a scanning step producing the virtual 3D object. The scan can be done with different techniques, with or without the help of the contextual knowledge, but always ends up in a numerical mock-up. This mock-up is represented as a cloud of points at the beginning of the scanning process, transformed into a mesh, and the textures are added at the end of the scanning process.

\section{- Contextual knowledge}

Historical researches extract the contextual knowledge from primary data, eventually helped by the data found from the scanned virtual 3D object. The modelling of this knowledge can be done in very different ways but the common ground is the link between the historical facts, or documents, and the 3D objects. There is a localisation of the knowledge in order to position this data into the final 3D City Model (3DCM).

\section{- Virtual artefact}

The final 3DCM is the fusion of the virtual 3D object and the contextual knowledge. This city model contains all the geometric and the semantic data associated with the mock-up. The professional and the public use it to explore the geometry or the knowledge of the mock-up. From these uses, secondary data can be extracted and added to the process into a feedback loop.

\section{DISCUSSION}

We merge geometric and semantic data to build a 3D City Model and we show that this two different kind of data are two complementary part of a 3DCM. So, in our approach, a 3DCM is obviously more than a geometric model. We show a global process to build this 3DCM with a geometric modelling and knowledge modelling done in parallel and influencing each other.

The generalized approach for historical mock-up acquisition and data modelling proposed in this paper is in an advance in the field of digital historical mock-ups and more generally in the field of historical information management. Indeed, where most of current historical digital mock-ups developments (cf. section 2) are limited to textured 3D geometric representations of an original mockup, the two analysed projects tend towards enriched historical information system, allowing new usages and interactions.

This advance is not limited to historical applications. Indeed, city models in general can beneficiate of this approach. Whatever the geometric data acquisition techniques, the data modelling approach 
is still valid because it links knowledge and city entities (geometric data) whatever the kind of data (existing, past or imaginary).

Historians are the main users of this framework as it helps to shape the data in giving a deeper understanding of the data modelling issue related to cultural heritage. Moreover by modelling formally this knowledge, historians could have another point of view on their research subjects, and thus giving them the opportunity to learn or discover new knowledge. Therefore our approach can be seen as an efficient research tool.

Everybody interested into history can also be seen as a potential user of our framework, as it is intended to spread the historical knowledge, and to receive secondary data source created by all the potential users. By giving an easy access to historical knowledge, our framework could also promote cultural heritage in general, by improving the cultural dissemination to a wider audience. For instance, enriched 3D CMs like the ones presented in this paper allows foreseeing interesting applications, such as augmented reality domain (guiding somebody in the real city with historical information) or museum interactive systems.

Considering the nodes of data model (cf. fig. 6) are linked to identified parts of the 3D city model, we can imagine paths through this data graph, leading the final user from one point to another, and considering that the path is related to a specific thematic (an abstract concept, or an historical event for example). Indeed, the system would automatically propose to the final user some paths according to his previous searches. Research works are currently in progress in this domain, by mathematically modelling these paths and constraints to be taken into account (historical time, geographical position, relationships and so on).

By building a data-modelling pipeline, the framework enhances the exploitation and the interoperability of 3DCM. We setup a basis for historically enriched 3DCM, and we hope this work could be the starting point for very fruitful exchange of views.

\section{CONCLUSION}

From two existing processes devoted to the data modelling of a historical mock-up, we analyse the common ground between these two processes in order to propose a unified approach and create a global data modelling process. This global process presents a generic way to acquire data from a mock-up and to perform two different modelling steps: geometric modelling by scanning the mock-up and knowledge modelling by studying the mock-up and the related archives. The fusion of geometry and knowledge allows to build a full 3DCM containing all the gathered data. Professionals and public can use this 3DCM to learn and decipher historical data, and then to add further material into the process following a reflexive approach.

Where further works are concerned, our goal is to use this global approach on others case studies, other mock-ups as we said in the previous section, but also other historical elements, allowing to extend the model. Each part of the model can be further enhanced by specific actions: fully automatize the scanning step; work tightly with historian scientist to develop the knowledge modelling; explore the possibilities of SIG and DB systems to fully integrate our model.

A geometric and semantic 3DCM build a link between knowledge and shapes, and a link between present and past. One of the key issues remains: How to build a link to the future, towards Computer Aided-Design and urban planning?

Regarding the Virtual Leodium project, the authors would like to thank the Artistic Collections of the University of Liege and the Cultural Heritage Centre of the University of Liege libraries network, respectively owner and curator of the Gustave Ruhl mock-up, for making accessible this wonderful piece of art. Michelle Pfeiffer has been a helpful student in this project and the authors would like to thank her for her work on this project: Pfeiffer M. 
“Approche critique de "La noble Cité de Liège en 1730 ” à travers l'étude du collège des Jésuites en Île. Évaluation par application d'un outil archéomatique" (Master en histoire de l'art et archéologie, orientation archéométrie), Université de Liège, Liège, Belgium, 2011.

Regarding the Nantes 1900 project, the authors would like to thank the Castle of the Dukes of Brittany (Château des ducs de Bretagne), owner of the Nantes historical mock-up.

\section{References}

[1] Langweil, D. Digitalization of Prague city, last step (2008)

[2] C. Chevrier, K. Jacquot, J.P. Perrin. "3D modelling of a town scale model.” EuroMed Conference (2010), 10p

[3] Frischer, B. "The Rome Reborn Project. How Technology is helping us to study history." $O p E d$. (2008)

[4] G. Guidi, B. Frischer, M. De Simone, A. Cioci, A. Spinetti, L. Carosso, L. Micoli, M. Russo, T. Grasso. "Virtualizing Ancient Rome: 3D Acquisition and Modeling of a Large Plaster-of-Paris Model of Imperial Rome.” Edited by SPIE. Videometrics VIII. San José: J.-Angelo Beraldin, Sabry F. El-Hakim, Armin Gruen, James S. Walton (2005), 119-133

[5] Fleury, P. "La rome antique sur l'internet." Informatics and statistics review for human sciences (1997)

[6] De Luca, L. (2006) Relevé et multi-représentations du patrimoine architectural; définition d'une approche hybride de reconstruction 3D d'édifices. Doctorat Conception, Paristech, ENSAM 2006, p. 217

[7] R. Billen, P. Blain, O. Donneau, S. Habraken, Y. Renotte \& M. Van Ruymbeke, 2009, "Virtual model of the city of Liège in the eighteen century - "Virtual Leodium"”. In Verly J. (Ed.), Proceedings of 3D Stereo MEDIA 2009, International 3D Stereo Film and Technology Festival (3D Stereo MEDIA), Liège, Belgium, 1-3 Dec. (2009)

[8] R. Billen, C. Carré, V. Delfosse, B. Hervy, F. Laroche, D. Lefèvre, M. Servières, M. Van Ruymbeke. "3D historical models: the case studies of Liege and Nantes." COST Action TU801 workshop on Semantic Enrichment of $3 D$ city models for sustainable urban development, April (2012) 